Check for updates

Cite this: J. Mater. Chem. B, 2021 9, 428 Accepted 27th November 2020

DOI: $10.1039 / d 0 t b 02454 f$

rsc.li/materials-b
Received 15th October 2020,

\section{Hybrid magneto-luminescent iron oxide nanocubes functionalized with europium complexes: synthesis, hemolytic properties and protein corona formation $\dagger$}

\author{
Luelc Souza da Costa, (D) *ab Latif Ullah Khan, (D) ${ }^{\text {ac }}$ Lidiane Silva Franqui, (D) ${ }^{a}$ \\ Fabrício de Souza Delite, (D) ${ }^{a}$ Diego Muraca, (D) ${ }^{b}$ \\ Diego Stéfani Teodoro Martinez (iD *a and Marcelo Knobel (D) *b
}

\begin{abstract}
The use of hybrid nanostructures based on magneto-luminescent properties is a promising strategy for nanobio applications and theranostics platforms. In this work, we carried out the synthesis and functionalization of iron oxide nanocubes (IONCs) to obtain multifunctional hybrid nanostructures towards biomedical applications. The IONCs were functionalized with tetraethylorthosilicate, thenoyltrifluoroacetone-propyl-triethoxysilane and europium(III)-dibenzoylmethane complexes to obtain the materials termed as $1 \mathrm{OCNCs} \mathrm{CSiO}_{2}, 1 \mathrm{ONCs} \mathrm{aSiO}_{2} \mathrm{TTA}$, IONCs@SiO 2 TTA-Eu and IONCs@SiO ${ }_{2}-T \mathrm{TA}-\mathrm{Eu}-\mathrm{DBM}$, respectively. Then, the biological interactions of these nanostructures with red blood cells - RBCs (hemolysis) and human blood plasma (protein corona formation) were evaluated. The XPS spectrocopy and EDS chemical mapping analysis showed that each domain is homogeneously occupied in the hybrid material, with the magnetic core at the center and the luminescent domain on the surface of the hybrid nanomaterial with a coreashell like structure. Futhermore, after each functionalization step, the nanomaterial surface charge drastically changed, with critical impact on RBC lysis and corona formation. While $10 \mathrm{NCs} \mathrm{CSiO}_{2}$ and $1 \mathrm{ONCs} \mathrm{CSiO}_{2}-T T A-E u-D B M$ showed hemolytic properties in a dosedependent manner, the IONCs $\mathrm{CSiO}_{2} \mathrm{TTA}$-Eu did not present any hemolytic effect up to $300 \mu \mathrm{g} \mathrm{mL}^{-1}$. Protein corona results showed a pattern of selective adsorption of proteins with each surface of the synthesized hybrid materials. However, as a general result, a suppression of hemolysis after protein corona formation in all tests was verified. Finally, this study provides a solid background for further applications of these hybrid magneto-luminescent materials containing new surface functionalities in the emerging field of medical nanobiotechnology.
\end{abstract}

\section{Introduction}

Multifunctional nanomaterials displaying magnetic and luminescent properties have excellent attributes for biomedical applications towards the development of theranostics platforms. ${ }^{1-4}$ Much of this interest is due to the different properties that can be combined or that can arise synergistically when two or more components are closely in contact at the nanoscale. ${ }^{5-8}$ For example, magnetic-fluorescent nanomaterials have applications in magnetic

\footnotetext{
${ }^{a}$ Brazilian Nanotechnology National Laboratory (LNNano), Brazilian Center for Research in Energy and Materials (CNPEM), Campinas, Sao Paulo, Brazil. E-mail: luelcs@gmail.com

${ }^{b}$ "Gleb Wataghim" Institute of Physics (IFGW), University of Campinas (Unicamp), Campinas, Sao Paulo, Brazil. E-mail: knobel@unicamp.br

${ }^{c}$ Synchrotron-Light for Experimental Science and Applications in the Middle East (SESAME), Allan, Jordan

† Electronic supplementary information (ESI) available. See DOI: 10.1039/ dotb02454f
}

resonance imaging (MRI), ${ }^{9,10}$ confocal and fluorescence imaging microscopies, ${ }^{6,11}$ cell isolation, drug delivery ${ }^{12,13}$ and in both opticand magnetohyperthermia. ${ }^{14,15}$

Regarding theranostics systems, those based on nanomagnets can achieve both diagnosis and therapy of cancer owing to their magnetic properties. ${ }^{16,17}$ Iron oxide nanocrystals and, in particular, magnetite $\left(\mathrm{Fe}_{3} \mathrm{O}_{4}\right)$, can be rather easily synthesized by different methods, including processes mediated by polyol, hydrothermal/solvothermal, sol-gel, co-precipitation, and thermal decomposition. Exploring these approaches, it is possible to obtain nanostructures with different sizes and morphologies, such as nanospheres, nanorods, nanowires, nanotubes and nanoflowers. ${ }^{16,18-20}$ Many studies concerning nanostructures based on iron oxide are directly related to the spherical shape of these structures. On the other hand, some studies have observed that in some magnetohyperthermia and theranostics applications iron oxide nanoparticles (NPs) with cubic shape have superior performance than nanospheres with 
similar dimensions. ${ }^{16,21}$ The overall magnetic properties, high biocompatibility and in vivo degradability, by means of a welldefined degradation path, make iron oxide nanocubes (IONCs) probably the best heat mediators available to date for clinical applications. $^{22-25}$

Furthermore, thermal decomposition is considered one of the more efficient methods to prepare magnetic nanocrystals with controlled and regular shape and morphology. This is important because it can greatly influence properties such as shape and magnetocrystalline anisotropy, and saturation magnetization, among others. ${ }^{26,27}$ The luminescent and magnetic nanomaterials can be obtained by coating or layer-by-layer deposition of rare earth phosphors, ${ }^{28-30}$ quantum dots $^{31}$ on magnetic core NPs, polymer assisted encapsulation or co-assembling of magnetic NPs and luminophores in single nanostructures, ${ }^{2,32}$ as well as functionalization of IONCs with dyes ${ }^{33}$ or luminescent rare earth complexes. $^{34}$

For biomedical applications of IONCs two prerequisites are essential: colloidal stability and low toxicity. ${ }^{35-37}$ Thus, surface chemistry engineering can be used as a strategy to functionalize the nanostructures surface with organic molecules such as polyethylene glycol (PEG) and carboxymethyl dextran, polymers, inorganic materials (such as silica), and noble metals (such as gold), among others. ${ }^{25,38-41}$ In fact, silica $\left(\mathrm{SiO}_{2}\right)$ is one of the most frequently used materials to functionalize nanostructures for biomedical applications. When one uses synthesis methods such as thermal decomposition, the produced NPs are dispersed in organic solvents such as toluene/hexane, which prevent the application of these nanostructures in biomedical applications. Thus, the functionalization of the surface with $\mathrm{SiO}_{2}$ allows dispersion of the compounds in aqueous media, avoids aggregation, improves colloidal stability, decreases toxicity and increases the biocompatibility of the resulting nanomaterials. ${ }^{42-44}$

The hemolytic assay is a simple, fast and robust in vitro bioassay to screening the biocompatibility/toxicity of nanomaterials. This bioassay is considered an useful tool to probe the influence of nanomaterial surface chemistry on red blood cells (RBCs), because the cell membrane disruption is easily detected by free hemoglobin released from RBCs (hemolysis) following the interaction with nanomaterials. ${ }^{45}$ Silica-based compounds deserve attention in the context of their toxicity to RBCs. It is known that the significant chemical affinity of the silanol groups with the phosphatidylcholine groups present in the cell membrane is related to high hemolytic effects. ${ }^{46}$ When silica nanoparticles interact with the surface of RBCs they can be wrapped, or engulfed, by the RBC. This effect is related to the surface energy of the silica nanoparticle and the energy of the membrane surface, which, in turn, is directly proportional to the curvature of the red cell. When the energy involved in this interaction is positive, there is no wrapping and, therefore, there is no hemolysis. However, when the energy is negative, there is a greater interaction between the surfaces and the silica particles are engulfed by the erythrocytes which, in turn, undergo lysis. ${ }^{46,47}$ This phenomenon is related to the size of the particles where it was shown that particles up to $200 \mathrm{~nm}$ are considered potentially safe candidates for intravascular applications of this class of materials. ${ }^{48}$
Nanomaterials in contact with blood plasma will interact rapidly with proteins and other biomolecules present in this biological fluid forming a biomolecular coating on the nanomaterial surface (protein corona). The nanomaterial-protein corona complexes will govern the cellular interaction and biological response of nanomaterials. ${ }^{49-51}$ Understanding the protein corona formation is therefore a key step towards biomedical application and safety evaluation of nanomaterials. ${ }^{52}$ Indeed, it is well known that protein corona formation affects the nanomaterial biodistribution, toxicity and cellular internalization. Considering intravenous administration and diagnostics developments, it is essential to understand the protein corona formation after the interaction of IOCNs hybrid nanostructures with human blood plasma. One of the biggest challenges today is the detailed control of the protein corona formation around the nanomaterial surfaces. After protein corona formation, many biological factors such as bioavailability, cellular uptake, transport, kinetics, circulation time, biodistribution, and toxicity of nanoparticles are greatly affected. ${ }^{53}$ The in vitro and in vivo biological impacts of nanoparticles have been evaluated to understand how biological responses are affected by protein corona formation. ${ }^{54,55}$ The composition and structure of the protein corona depends upon physicochemical properties of nanoparticles (e.g., size, shape, and composition), the nature of the physiological environment (e.g., cell cytoplasm, interstitial fluid, and blood) as well as the duration of exposure. ${ }^{56}$ Despite these important findings, to date there is little information about the influence of surface chemistry modification of IONCs@SiO materials on their hemolytic properties and protein corona formation.

In this work, we carry out the synthesis and characterization of IONCs with superior size and morphology control, functionalized with silica and luminescent europium(III) $\beta$-diketonate compounds using dibenzoylmethane (DBM) as an external ligand, with the objective of studying the influence of this surface modification over biological interactions with red blood cells (hemolysis) and human blood plasma (protein corona formation).

\section{Experimental section}

\section{Chemicals}

Phenyl ether (99\%), oleylamine ( $>70 \%$ ), oleic acid (90\%), iron(III) acetylacetonate (99\%), 1,2-fexadecanediol (90\%), n-hexane (97\%), cyclohexane (99.5\%), Igepal ${ }^{\circledR} \mathrm{CO}-520$, tetraethylorthosilicate (TEOS, $>99 \%)$, 2-thenoyltrifluoroacetone (99\%), dibenzoylmethane (98\%) ammonia solution (25-28 wt\%), ethanol absolute (ACS grade), $\mathrm{N}, \mathrm{N}$ dimethylformamide - DMF (ACS grade), tetrahydrofuran - THF anhydrous, were purchased from Sigma Aldrich. The water used in all experiments was ultrapure. All other chemicals were used as received without further purification.

\section{Synthesis of iron oxide nanocubes}

The iron oxide nanocubes were synthesized by the modified polyol process based on early reported procedure, as follows. ${ }^{57}$ $\mathrm{Fe}(\mathrm{acac})_{3}$ (2 mmol), 1,2-hexadecanediol (10 mmol), oleic acid 
(6 mmol), oleylamine (6 mmol), and phenyl ether $(20 \mathrm{~mL})$ were mixed and magnetically stirred under a flow of nitrogen. The mixture was heated to $200{ }^{\circ} \mathrm{C}$ for $30 \mathrm{~min}$ at the rate of $5{ }^{\circ} \mathrm{C} \min ^{-1}$. At this stage the nitrogen flow is interrupted, and then heated to reflux $\left(300{ }^{\circ} \mathrm{C}\right)$ for $30 \mathrm{~min}$. The black-brown mixture was cooled down to room temperature by removing the heat source. Under ambient conditions, ethanol $(40 \mathrm{~mL})$ was added to the mixture, and a black material was precipitated and separated via centrifugation (8000 rpm, $10 \mathrm{~min}$ ). The black product was dispersed in hexane in the presence of oleic acid $(\sim 0.05 \mathrm{~mL})$ and oleylamine $(\sim 0.05 \mathrm{~mL})$. The final product (IONCs) was then precipitated with ethanol, centrifuged ( $8000 \mathrm{rpm}, 10 \mathrm{~min}$ ) to remove the solvent, and finally re-dispersed into hexane.

\section{Silica coating of iron oxide nanocubes}

$\mathrm{SiO}_{2}$ coating was performed by means of the formation of a water in-cyclohexane reverse microemulsion. ${ }^{58}$ Typically, $0.5 \mathrm{~mL}$ of Igepal CO-520 was dispersed in $11 \mathrm{~mL}$ of cyclohexane and sonicated for $10 \mathrm{~min}$, then $2 \mathrm{~mL}$ of the as-prepared $\mathrm{Fe}_{3} \mathrm{O}_{4}$ NCs dispersion was added to the above solution with continued mechanical stirring. A total of $200 \mu \mathrm{L}$ of ammonia solution (28 wt\%) was added to the solution and $300 \mu \mathrm{L}$ of tetraethyl orthosilicate (TEOS) were then added to the brown dispersion. The TEOS was added in fractions of $50 \mu \mathrm{L}$ every $12 \mathrm{~h}$ of reaction at room temperature, adding up to 72 hours of reaction. Finally, methanol was combined to disrupt the reverse microemulsion, and the silica-coated IONCs were extracted via the methanol phase. They were collected by centrifugation and redispersed in water, methanol, or ethanol.

\section{Surface functionalization of IONCs@SiO $\mathrm{I}_{2}$ with rare earth complex}

The nanostructures were prepared by functionalizing the surface of IONCs@SiO $\mathrm{NPs}_{2}$ with thenoyltrifluoroacetonate (TTA) ligand, according to the reported procedure. ${ }^{59}$ The mixture of $0.125 \mathrm{~g}(0.56 \mathrm{mmol})$ of HTTA and $0.028 \mathrm{~g}(1.125 \mathrm{mmol})$ of $\mathrm{NaH}$ in dry DMF/THF $(1: 3, \mathrm{v} / \mathrm{v})$ was stirred at room temperature for $30 \mathrm{~min}$. Thereafter, $0.134 \mathrm{~g}(0.56 \mathrm{mmol})$ of 3 -chloropropyltriethoxysilane (CPTES) was added and heated at reflux for $72 \mathrm{~h}$, to obtain the TTA modified propyl-triethoxysilane (TTAPTES) product, which was dried in vacuum desiccator and used

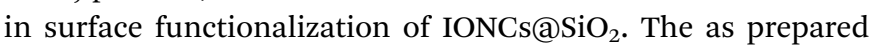
$0.06 \mathrm{~g}$ of IONCs@SiO${ }_{2}$ NPs were homogenously dispersed in Milli-Q water and propanol $(1: 4 \mathrm{v} / \mathrm{v} \%)$ by ultrasonication and $200 \mu \mathrm{L}$ of ammonia solution ( $28 \mathrm{wt} \%$ ) was added. Thereafter, $0.020 \mathrm{~g}$ of TTA-PTES solution in propanol was added and stirred overnight at room temperature. The product was washed with ethanol and Milli-Q water by centrifugation to remove the excess of TTA and impurities, then dried in vacuum to get brown color IONCs@SiO $\mathrm{S}_{2}$-TTA nanomaterials.

The core-shell luminescent and magnetic nanomaterials were synthesized by a general procedure, involving the chemical preparation of $\mathrm{Eu}^{3+}$ complexes on the surface of IONCs@SiO ${ }_{2}$-TTA nanostructures. In a typical procedure, to a suspension of $0.06 \mathrm{~g}$ of IONCs@SiO ${ }_{2}-\mathrm{TTA}$ in $30 \mathrm{~mL}$ of ethanol was added $0.180 \mathrm{~g}$ of the DBM ligand. After stirring the solution for $10 \mathrm{~min}$, few drops of $\mathrm{NH}_{3} \cdot \mathrm{H}_{2} \mathrm{O}(28-30 \mathrm{v} / \mathrm{v} \%)$ were added and heated to $50{ }^{\circ} \mathrm{C}$. Subsequently, a solution of 0.5 equivalent (relative to DBM) of the hydrated europium chloride in ethanol was added with the adjustment of $\mathrm{pH}$ to 8 by dropwise addition of $\mathrm{NH}_{3} \cdot \mathrm{H}_{2} \mathrm{O}(28-30 \mathrm{v} / \mathrm{v} \%)$. The reaction mixture was continuously stirred at $50{ }^{\circ} \mathrm{C}$ for $4 \mathrm{~h}$. Thereafter, the temperature was adjusted to ambient temperature and the reaction mixture was further stirred overnight. The resultant products were collected by magnetic separation with permanent magnet and washed with ethanol, methanol, Milli-Q water and chloroform to remove the excess of $\mathrm{Eu}^{3+}$-DBM complex, then were dried under reduced pressure, and stored in vacuum desiccator. The obtained magneto-luminescent nanostructures were named as IONCs@SiO ${ }_{2}-\mathrm{TTA}-\mathrm{Eu}-\mathrm{DBM}$.

\section{Materials characterization}

Several experimental techniques were used to characterize the colloidal IONCs with engineered surface chemistry by $\mathrm{SiO}_{2}-$ TTA-Eu ${ }^{3+}-$ DBM complex. To evaluate the morphological and crystalline characteristics, transmission electron microscopy (TEM) analyses were performed by using few milligrams of the samples, in the powder form or few drops of colloidal IONCs, dispersed in isopropyl alcohol or hexane, then sonicated for $15 \mathrm{~min}$. Two drops of the dispersion were placed into ultra-thin carbon coated copper grids. After deposition, the samples were dried at room temperature overnight. The images were acquired using a JEOL JEM 2100F LaB6 operating at an accelerating voltage equal to $200 \mathrm{kV}$, Spot Size 1, Alpha Selector 3 and equipped with a TV (Gatan ES500 W) and with an X-Max N 80 T detector of Oxford Instruments Aztec. High-Resolution TEM (HRTEM), High Angle Annular Dark-Field Scanning Transmission Electron Microscopy (HAADF-STEM), and STEM energy-dispersive spectroscopy (STEM-EDS) analyses were obtained using a same equipment. TEM EDS microanalysis software was used for EDS data analyses.

The surface chemical composition of the IONCs@SiO ${ }_{2}-\mathrm{TTA}-$ $\mathrm{Eu}^{3+}$-DBM NPs was analyzed with K-Alpha X-ray Photoelectron Spectrometer (XPS) from Thermo Fisher Scientific Inc., using monochromatic Al K $\alpha$ X-rays $(1486.6 \mathrm{eV})$ and spot size of $300 \mu \mathrm{m}$. Survey spectra were recorded by running the scans in the 0-1350 eV range at three different areas for each sample, with $400 \mu \mathrm{m}$ of spatial resolution, and using pass energy of $200 \mathrm{eV}$. The high resolution spectra were recorded in the bonding energy ranges of $\mathrm{C} 1 \mathrm{~s}, \mathrm{O} 1 \mathrm{~s}$ and $\mathrm{Fe} 2 \mathrm{p}$ signals, using an energy step size of $0.1 \mathrm{eV}$ and pass energy of $50 \mathrm{eV}$. The deconvolution and background subtraction were carried out by fitting the peaks on Avantage 5.89 software (Thermos Scientific).

Magnetic measurements were performed on a MPMS superconducting quantum interference device (SQUID) from Quantum Design Inc. Hysteresis curves were measured within the magnetic field of $\pm 30 \mathrm{kOe}$ at two temperatures ( 5 and $300 \mathrm{~K}$ ). Temperature dependent magnetization studies, zero field cooled (ZFC), and field cooled (FC) curves were recorded under a magnetic field of 50 Oe. In a ZFC protocol, the sample was cooled from room temperature to $5 \mathrm{~K}$ without any magnetic 
field, and the magnetization was measured during heating from $5-300 \mathrm{~K}$ at $2 \mathrm{~K} \mathrm{~min}^{-1}$ under the magnetic field of 50 Oe. In a FC protocol, the same sample was cooled down to $5 \mathrm{~K}$ under the 50 Oe magnetic field, and the magnetization was recorded during heating mode from 5-300 K under the same heating rate.

The luminescence spectra of the bifunctional IONCs@SiO ${ }_{2}^{-}$ TTA-Eu-DBM NPs were recorded at room temperature with a HORIBA Jobin Yvon Fluorolog-3 spectrofluorometer using a $450 \mathrm{~W}$ xenon lamp as an excitation source, double-grating monochromators and CCD detector. Each sample was measured three times in three replicates forms consecutively.

\section{Hemolytic assays}

The human blood (type $\mathrm{O}^{+}$) was provided by the Hemocenter from the University of Campinas (Campinas, São Paulo, Brazil). Red blood cells $\left(\mathrm{RBCs}^{-}\right.$) were obtained from the human blood by washing an aliquot of $5 \mathrm{~mL}$ of blood with $40 \mathrm{~mL}$ of a $0.15 \mathrm{~mol} \mathrm{~L}^{-1} \mathrm{NaCl}$ solution through centrifugation at $10000 \mathrm{rpm}$ and $4{ }^{\circ} \mathrm{C}$ for $10 \mathrm{~min}$. After three washing steps, a suspension consisted of $10 \%(\mathrm{v} / \mathrm{v}) \mathrm{RBCs}$ in $0.15 \mathrm{~mol} \mathrm{~L}^{-1} \mathrm{NaCl}$ solution was prepared to be used in the hemolysis assay. To investigate the hemolytic effect of IONCs, IONCs@SiO ${ }_{2}-\mathrm{TTA}$ and IONCs@SiO ${ }_{2}-\mathrm{TTA}-\mathrm{Eu}-\mathrm{DBM} \mathrm{NPs}$, increasing concentrations of each one $\left(15,30,75,150,225\right.$ and $\left.300 \mu \mathrm{g} \mathrm{mL}^{-1}\right)$ were incubated with RBCs for $1 \mathrm{~h}$. For this, the volume of each nanoparticle dispersion was diluted in the same volume of a $0.3 \mathrm{~mol} \mathrm{~L}^{-1} \mathrm{NaCl}$ solution, then a $0.15 \mathrm{~mol} \mathrm{~L}^{-1} \mathrm{NaCl}$ solution completed the remaining volume of $900 \mu \mathrm{L}$ and finally, $100 \mu \mathrm{L}$ of RBCs were added at last. The positive control consisted of $900 \mu \mathrm{L}$ of deionized water and $100 \mu \mathrm{L}$ of a $10 \%$ RBC suspension. The negative control consisted of $900 \mu \mathrm{L}$ of a $0.15 \mathrm{~mol} \mathrm{~L}^{-1} \mathrm{NaCl}$ solution and $100 \mu \mathrm{L}$ of the $10 \%$ RBC suspension. After the incubation period, the tubes were centrifuged at $10000 \mathrm{rpm}$ and $4{ }^{\circ} \mathrm{C}$ for $10 \mathrm{~min}$. The quantification of released hemoglobin was carried out by recording the absorbance of hemoglobin by UV-vis spectroscopy at $540 \mathrm{~nm}$. The percentage of hemolysis was calculated by using the linear equation $y=m x+c$, where the percentage of hemolysis $(x)=[$ optical density $(y)-$ negative control optical density $(c)] /[($ positive control optical density negative control optical density)/100] $(\mathrm{m})$. All tests were performed in triplicate.

The hemolytic effect of the DBM ligand was also analyzed by applying the same protocol and concentrations $(15,30,75$, 150, 225 and $300 \mu \mathrm{g} \mathrm{mL} \mathrm{m}^{-1}$, respectively) used for the hybrid materials. Besides, the hemolysis assay was also performed with the three nanocomposites after their interaction with plasma proteins at the higher nanocomposites concentration $\left(300 \mu \mathrm{g} \mathrm{mL}{ }^{-1}\right)$.

\section{Protein corona assays}

Preserved type $\mathrm{O}^{+}$human plasma was obtained from the Hemocenter from the University of Campinas (Campinas, São Paulo, Brazil). For the protein corona studies ${ }^{60}$ the plasma was previously centrifuged three times at $14000 \mathrm{rpm}$ and $4{ }^{\circ} \mathrm{C}$ for $10 \mathrm{~min}$, and the supernatant was used for the experiments. The nanocomposites dispersions $\left(1.0 \mathrm{mg} \mathrm{mL}^{-1}\right.$ in deionized water) were sonicated for $30 \mathrm{~min}$ in an ultrasound bath (Cole-Parmer 8891 ) to produce the stock dispersion. Then, $100 \mu \mathrm{L}$ of each nanocomposite stock dispersion was incubated with 55\% plasma in PBS solution $\mathrm{pH} 7.4$ for $1 \mathrm{~h}$ at $37^{\circ} \mathrm{C}$ in thermoblocks (SmartBlock, Eppendorf). After the incubation period, the tubes were centrifuged at $14000 \mathrm{rpm}$ and $4{ }^{\circ} \mathrm{C}$ for $1 \mathrm{~h}$, and the supernatants were discarded. The obtained pellets (comprising the nanocomposite-protein corona complexes) were washed three times with the PBS solution $\mathrm{pH} 7.4$ to remove the excess of softly adsorbed proteins on the nanocomposite surface, obtaining the nanomaterial/strongly adsorbed proteins complex (hard corona). The final pellet was resuspended in a buffer (containing $62.5 \mathrm{mM}$ Tris-HCl, 2\% (w/v) SDS, 10\% glycerol, and $0.01 \%(\mathrm{w} / \mathrm{v})$ bromophenol, $\mathrm{pH}$ 6.8) and heated for $3 \mathrm{~min}$ at $99{ }^{\circ} \mathrm{C}$. From this resulting suspension, $15 \mu \mathrm{L}$ was applied to a $15 \%$ SDS-polyacrylamide gel. The gel was stained with Coomassie Blue for the identification and visualization of strongly adsorbed proteins (hard corona proteins) on the nanocomposites.

\section{Results and discussion}

The polyol process was used to synthesize IONCs nanostructures. This method is widely used, usually associated with thermal decomposition, to synthesize NPs with controlled shape, size, and chemical composition, as well as narrow size distribution. ${ }^{18,61,62}$ However, many parameters can influence the quality of the NPs synthesized by this method, such as the nature of the solvent, metal precursor, surfactant, besides the applied heating rate and annealing time, respectively. Guardia et al. showed that the solvent to surfactant ratio used in the synthesis of IONCs influenced the size of nanostructures. Also, the decomposition of the solvent into smaller organic species acts on the stabilization of the structure and consequently on the final size and morphology of the structures. ${ }^{18}$

In this work two experiments were carried out with two different annealing times on reflux condition, 30 and 90 minutes, respectively, obtaining two different sizes of IONCs. From TEM images, the first IONCs sample (30 minutes annealing time), presented a cuboidal type shape with an average diagonal of $20 \pm 2.6 \mathrm{~nm}$, which were measured via ImageJ software, see Fig. 1 . The sample displays a slightly wide particle size distribution with polydispersity degree $(\mathrm{SD} / x)$ around $13 \%$ (Fig. S1 of the ESI $\dagger$ ). The second sample (annealing time $90 \mathrm{~min}$ ) have bigger nanoparticles with a perfect cubic shape, with edge dimensions around $40 \mathrm{~nm}$ (Fig. S2 of the ESI $\dagger$ ). In the longer time of annealing the Ostwald ripening phenomenon is favored, when smaller particles in solution dissolve and deposit on larger particles in order to reach a more thermodynamically stable state wherein the surface to volume ratio is minimized. ${ }^{63-65}$ Only the smaller IONCs were used for the following steps, since the larger IONCs presented lower colloidal stability, a crucial feature for the $\mathrm{SiO}_{2}$ coating step. 

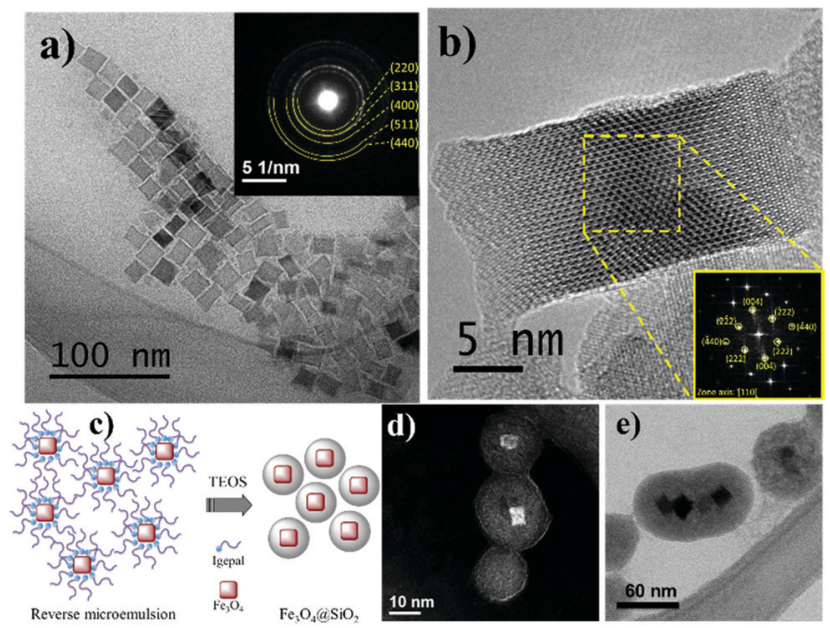

Fig. 1 (a) TEM images of IONCs and SAED analysis (inset), indicating the magnetite crystalline phase for IONCs; (b) HRTEM of IONCs and FFT of the region marked (inset) corresponds to the pattern of the zone axis [110] of magnetite structure; (c) scheme of reaction within the micelle promoting the hydrolysis reaction and the silica coating on IONCs ( $d$ and e) are images obtained by TEM in scanning mode (STEM) that can be obtained in the dark field or bright field ((d) and (e) respectively) using a HAADF detector. The image show that $I O N C s \mathrm{CSiO}_{2}$ material have a morphology of coreashell like structure.

The analysis of SAED, inset Fig. 1a, gives indications that the crystalline structure of the IONCs corresponds to the inverse magnetite spinel structure $\left(\mathrm{Fe}_{3} \mathrm{O}_{4}-\mathrm{PDF}\right.$ : 19-629). This was corroborated with HRTEM image analysis, with FFT of the region marked in the inset of Fig. 1b, corresponding to the zone axis [110] of magnetite structure as well as the presence of several families of crystalline planes, such as (222), (440) and (004).

During the silica coating process by reverse micelle microemulsion route, the IONCs dispersion in cyclohexane presents some stabilizer oleic acid and oleylamine molecules is stirred during $1 \mathrm{~h}$. This process allows these molecules favor the NPs percolation into the reverse micelle formed by Igepal ${ }^{\mathbb{R}}$ in cyclohexane. Owing to the small micelle size, an individual magnetic nanoparticle is expected to be encapsulated in each micelle avoiding a silica matrix containing IONCs formation, generally observed in direct TEOS hydrolysis process. ${ }^{66}$ In this way, when TEOS and $\mathrm{NH}_{4} \mathrm{OH}$ are added, they percolate and react within the micelle promoting the hydrolysis reaction and the silica coating on IONCs as shown in the scheme of Fig. 1c. According to TEM images Fig. 1d and e, the IONCs were coated with a homogeneous silica layer of around $12 \mathrm{~nm}$ of thickness resulting in nanostructures with average diameter of around $50 \mathrm{~nm}$. Some structures of IONCs@SiO${ }_{2}$ presented multiple nuclei in a single structure due to the fact that the TEOS hydrolysis process occurs in micelles containing two or more particles of IONCs. Likely, this occur due to the surface step of ligand exchanging, which may in turn destabilize the colloid and cause agglomeration of the particles due to their magnetic nature. ${ }^{44}$

The surface functionalization of IONCs@SiO ${ }_{2}$ nanoparticles was performed through covalently anchoring with the thenoyltrifluoroacetone-propyl-triethoxysilane moiety to give IONCs@SiO ${ }_{2}$-TTA. This is provided a platform to add the $\mathrm{Eu}^{3+}$ ion to the NPs surface via metal-ligand interaction, leading to formation of IONCs@SiO ${ }_{2}-\mathrm{TTA}-\mathrm{Eu}$. Therefore, the $\mathrm{Eu}^{3+}$ complex was ligated to the surface of IONCs@SiO - TTA nanostructures, using dibenzoylmethane (DBM) as an external ligand to produce highly luminescent IONCs@SiO ${ }_{2}-\mathrm{TTA}-\mathrm{DBM}$ nanocomposites, as schematically illustrated in the Scheme 1. The samples were then characterized by XPS, FT-IR and chemical mapping in the STEM mode.

The surface elements composition of the IONCs@SiO ${ }_{2}-\mathrm{TTA}-$ Eu-DBM NPs was studied by XPS technique and their respective spectra are shown in Fig. 2. The survey spectrum of these NPs shows the most abundant $\mathrm{C}, \mathrm{O}$ and Eu elements, suggesting the presence of $\mathrm{Eu}^{3+} \mathrm{DBM}$ complex on the surface of IONCs@SiO NPs (Fig. 2a). The peaks in the binding energies ranges of $\mathrm{C} 1 \mathrm{~s}$ and $O$ 1s signals are aroused from the $\beta$-diketonate ligands of the magneto-luminescent NPs. The high intensity peak of $\mathrm{Eu}^{3+}$ signal indicates the presence this element on the surface of

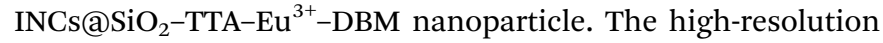
XPS spectrum in the Fe $2 \mathrm{p}$ region shows the peaks of Fe $2 \mathrm{p}_{3 / 2}$ $(\mathrm{BE}=710.78 \mathrm{eV})$ and $\mathrm{Fe} 2 \mathrm{p}_{1 / 2}(\mathrm{BE}=724.38 \mathrm{eV})$, ascribed to the convolution of both $\mathrm{Fe}^{2+}$ and $\mathrm{Fe}^{3+}$ signals in $\mathrm{Fe}_{3} \mathrm{O}_{4}$ (Fig. 2b). The interesting result may be observed in the deconvoluted $\mathrm{O} 1 \mathrm{~s}$ spectrum (Fig. 2c), which shows a peak at $\sim 531.0 \mathrm{eV}$ that can be attributed to $\mathrm{Fe}-\mathrm{O}$ bond $\left(\mathrm{Fe}_{3} \mathrm{O}_{4}\right)$ and there can be also a contribution of the formal $\mathrm{Eu}^{3+}$ oxidation state $(\mathrm{Eu}-\mathrm{O})$ of $\mathrm{Eu}^{3+}$ complex. The overlapped dominant peak located at higher binding energy ( $\mathrm{BE} \geq 532 \mathrm{eV}$ ) is attributed to the $\mathrm{C}-\mathrm{O}$ bonding and the one at $\sim 533 \mathrm{eV}$ corresponds to the Si-O bonding. The Eu 4d XPS spectrum (Fig. 2d and e) shows main peaks in the characteristic $\mathrm{Eu}^{3+}$ binding energies that can be assigned as: $\mathrm{Eu}^{3+} 4 \mathrm{~d}_{5 / 2}(\mathrm{BE}=136.8 \mathrm{eV})$ and $\mathrm{Eu}^{3+} 4 \mathrm{~d}_{3 / 2}(\mathrm{BE}=142.5 \mathrm{eV})$, respectively, for the IONCs@ $\mathrm{SiO}_{2}-\mathrm{TTA}-\mathrm{Eu}^{3+}-\mathrm{DBM}$. In addition, very weak intensity bands for the $\mathrm{Eu}^{2+}$ ion can be observed in

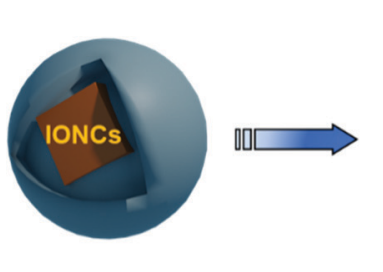

IONCs@SiO

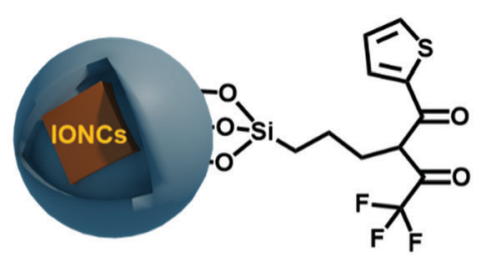

IONCs@SiO 2 -TTA

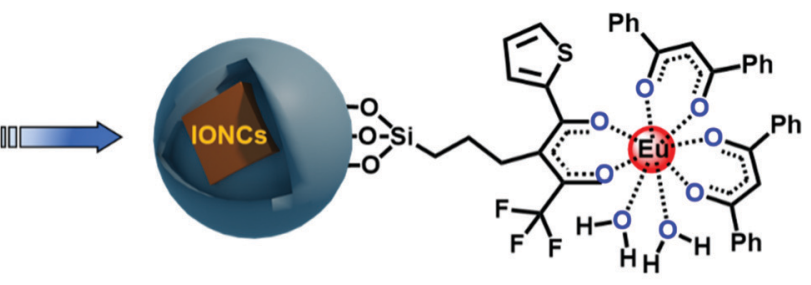

IONCs@SiO $\mathrm{SiT}_{2}$-TTA-Eu-DBM

Scheme 1 Illustration of each step of the functionalization of the IONCs@SiO $\mathrm{S}_{2}$ nanomaterial. 

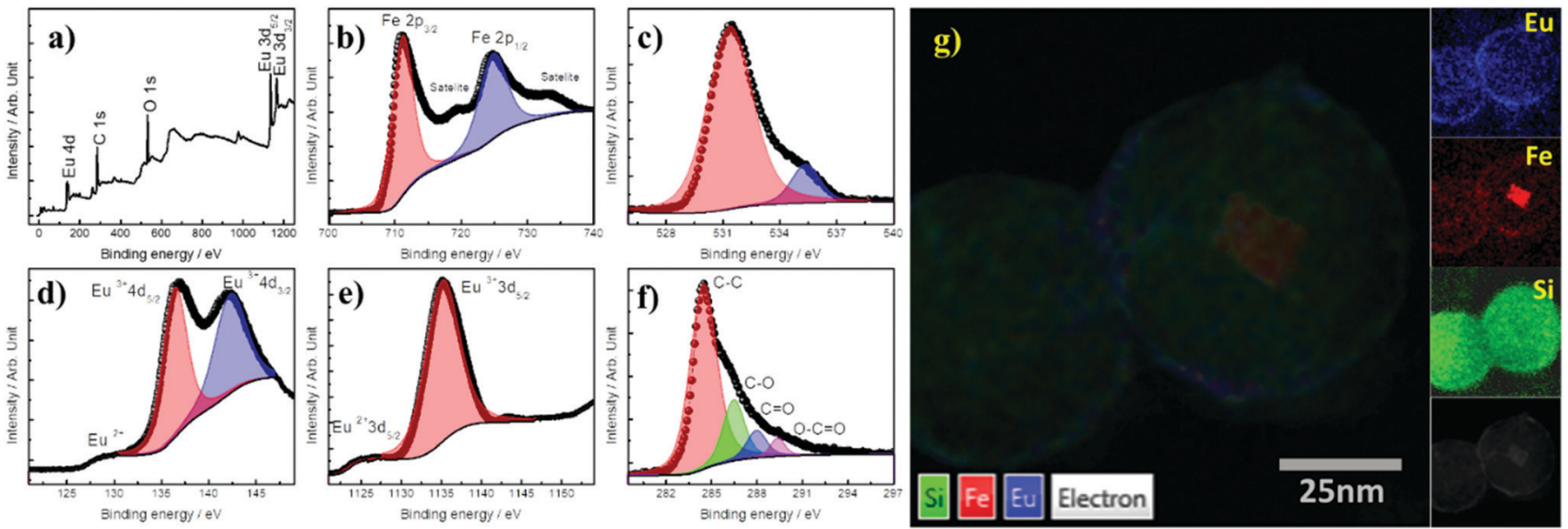

Fig. 2 XPS spectra of the IONCs@SiO ${ }_{2}-T T A-E u-D B M$ NPs including wide-scan or survey (a), high resolution spectra measured in bonding energy ranges of $\mathrm{Fe} 2 \mathrm{p}$ (b), $\mathrm{O}$ 1s (c), Eu 4d (d), Eu 3d (e) and C 1s (f) signals. HAADF-STEM image and (g) EDS elemental mapping of IONCs@SiO ${ }_{2}-T T A-E u-D B M$ and individual signal for Eu, Fe and $\mathrm{Si}$, respectively (inset of $(\mathrm{g})$ ).

the Eu $4 d$ spectrum, which are also observable in the Eu 3d one (Fig. 2e) at bonding energies of $1125.4 \mathrm{eV}$. The deconvoluted $\mathrm{C}$ 1s signal high resolution spectrum (Fig. 2f) exhibits peaks attributed to the $\mathrm{C}-\mathrm{C}(\mathrm{BE}=\sim 284.7 \mathrm{eV}), \mathrm{C}-\mathrm{O}(\mathrm{BE}=\sim 286 \mathrm{eV})$, $\mathrm{C}=\mathrm{O}(\mathrm{BE}=\sim 287.8 \mathrm{eV})$ and $\mathrm{O}-\mathrm{C}=\mathrm{O}(\mathrm{BE}=\sim 289 \mathrm{eV})$ bonds respectively, of the TTA and DBM organic molecules.

The HAADF-STEM image and the corresponding elemental mapping (Fig. 2g) obtained from STEM-EDS revealed that the Fe atoms (red signal) were localized in the core region of the IONCs@SiO ${ }_{2}-\mathrm{TTA}-\mathrm{Eu}^{3+}-\mathrm{DBM}$, while for the $\mathrm{SiO}_{2}$ domain (green signal), correspond the shell of the nanostructure mean size that was found to be $\sim 15 \mathrm{~nm}$, which corroborates the formation of a uniform shell around of the IONCs core. The chemical mapping allows one to observe that the signal attributed to the $\mathrm{Eu}$ atoms (blue signal) is homogeneously distributed over the $\mathrm{SiO}_{2}$ layer, conferring multifunctionality to the nanostructure with both magnetic and luminescent properties. This observation is reinforced when the EDS spectrum is collected with the longest exposure time as shown in Fig. S3 of the ESI. $\dagger$

The magnetic properties ( $M$ vs. $H$ curves) were measured at 300 and $5 \mathrm{~K}$, respectively, with the applied magnetic field cycling between -30 and $+30 \mathrm{kOe}\left(1 \mathrm{Oe}=79.577 \mathrm{~A} \mathrm{~m}^{-1}\right)$. The hysteresis loops of the IONCs, IONCs@SiO ${ }_{2}$, IONCs@SiO $2-T T A-E u-D B M$ nanomaterials (Fig. 3a) show a near superparamagnetic behavior at $300 \mathrm{~K}$ with null or very low value of coercive field $\left(H_{\mathrm{C}}\right)$. For the IONCs, the magnetization per mass of material at $H=20 \mathrm{kOe}$ and $T=300 \mathrm{~K}$, exhibits a value of $14.8 \mathrm{emu}^{-1}$. After coating with silica (IONCs@SiO ${ }_{2}$ ) a considerable decrease was observed, down to $5.4 \mathrm{emu}^{-1}$ indicating a large amount of non-magnetic mass contribution from the silica shell. Finally, due to the addition of the TTA-Eu-DBM complex, the magnetization further decreased to a value near $1.1 \mathrm{emu} \mathrm{g}^{-1}$.

The observed decrease in the measured magnetization values ( $H=30 \mathrm{kOe}$ and $T=300 \mathrm{~K}$ ) for the IONCs@SiO${ }_{2}-\mathrm{TTA}-\mathrm{Eu}-\mathrm{DBM}$, when compared to the IONCs simple nanostructure, can be attributed to the presence of a wide silica shell and successive organic coating on the surface of IONCs nanocubes. In addition, the almost null coercive field on the magnetization curves indicates a nearly superparamagnetic behavior at RT for the IONCs, IONCs@SiO ${ }_{2}$ and IONCs@SiO ${ }_{2}-\mathrm{TTA}-\mathrm{Eu}-\mathrm{DBM}$ nanomaterials.

The low temperature $(5 \mathrm{~K})$ results show a similar behavior when compared to the measurements at $300 \mathrm{~K}$. However, the hysteresis loops show larger saturation magnetization values (Fig. 3b), as was also reported previously for this kind of nanosystems. ${ }^{67}$ Also, the observed increase in the coercive field is attributed to the surface effect induced by the silica, that could generate surface spin freezing effects.

The temperature dependence magnetization at the ZFC and FC modes (Fig. 3c) were measured with an applied field of 50 Oe, scanning between 2 and $300 \mathrm{~K}$ for the three samples. Although the measurements do not show a "classic" superparamagnetic behavior, with a well-defined blocking temperature, an irreversibility temperature is observed close to room temperature. A Morin transition ${ }^{68}$ is noticed for IONCs, evidencing the possible presence of small amount other magnetic phases. Such phases were not observed by other experimental technique such as electron diffraction, for example, fact that make us think that it is a tiny minority phase. This possible mixture of magnetic phases was observed previously on iron oxide NPs obtained by thermal decomposition. ${ }^{69}$

Among the luminescent trivalent rare earth materials reported in the literature, ${ }^{70,71} \mathrm{Eu}^{3+}$ ions act as efficient emitting centers owing to the very intense red monochromatic color displayed by their compounds. In addition, the principal emitting level $\left({ }^{5} \mathrm{D}_{0}\right)$ of the $\mathrm{Eu}^{3+}$ ion is nondegenerate showing the emission bands arising from the ${ }^{5} \mathrm{D}_{0} /{ }^{7} \mathrm{~F}_{J}$ transitions $(J=0,1,2,3$ and 4) and can provide information about the local symmetry based on their ligand field splitting with a long lifetime of the emitting level. Generally, the organic ligand can act as sensitizer for the $\mathrm{Eu}^{3+}$ ions due to their $4 \mathrm{f}$ intra-configurational energy level structures through the so-called antenna effect.

Accordingly, the IONCs@SiO ${ }_{2}$ nanoparticles manifested negative surface charge (Table 1), however, after anchoring the $\mathrm{Eu}^{3+}$ ion 

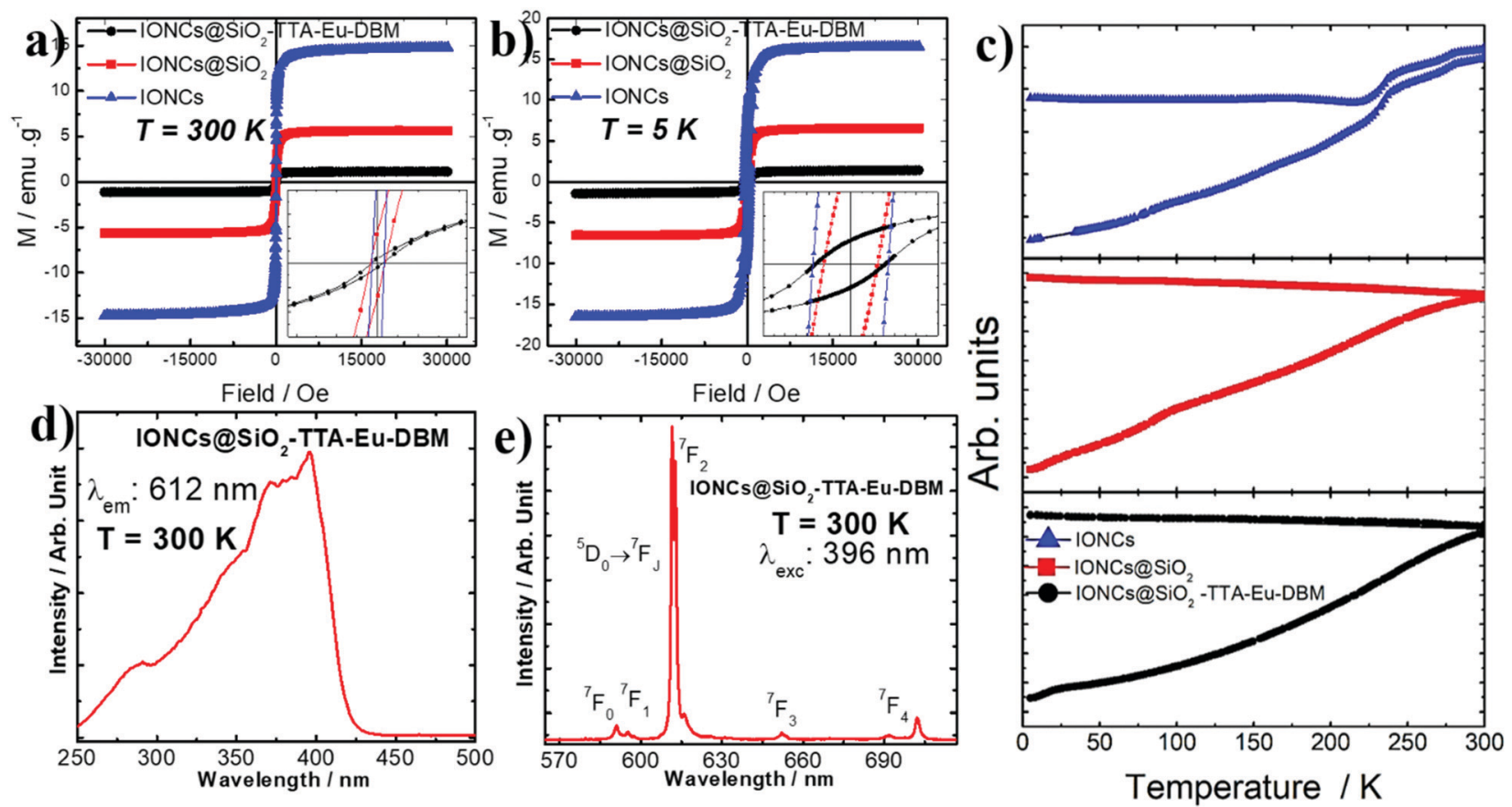

Fig. 3 Magnetization as a function of applied field of the $\mathrm{Fe}_{3} \mathrm{O}_{4}\left(\mathrm{aSiO}_{2}, \mathrm{Fe}_{3} \mathrm{O}_{4} \mathrm{QSiO}_{2}-\mathrm{TTA}-\mathrm{Eu}, \mathrm{Fe}_{3} \mathrm{O}_{4} \mathrm{QSSiO}_{2}-\mathrm{TTA}-\mathrm{Eu}-\mathrm{DBM}\right.$ hybrid materials at (a) room temperature and (b) $5 \mathrm{~K}$, as well as zoom-in of the $\mathrm{M}-\mathrm{H}$ curves in low field regions (insets). (c) Zero field cooling and field cooling measurements measured with $50 \mathrm{Oe}$ applied field. Luminescence spectra of the $\mathrm{Fe}_{3} \mathrm{O}_{4} \mathrm{CSiO}_{2}-\mathrm{TTA}-\mathrm{Eu}-\mathrm{DBM}$ hybrid materials recorded at room temperature (300 $\mathrm{K}$ ): (d) excitation spectrum and (e) emission spectrum.

on the surface of the IONCs@SiO 2 -TTA, the material presented positive surface charge, which was expected, since the presence of $\mathrm{Eu}^{3+}$ ions on the surface indicates that they are ligated to the IONCs@SiO ${ }_{2}$-TTA structure through metal-ligand interaction. Additionally, using DBM as an external ligand in order to potentiate the luminescent characteristics of the nanostructure, the surface charge of the IONCs@SiO ${ }_{2}$-TTA-Eu-DBM nanocomposite became negative. The excitation spectrum (Fig. 3d) of the IONCs@$\mathrm{SiO}_{2}-\mathrm{TTA}-\mathrm{Eu}-\mathrm{DBM}$ nanoparticle was recorded at $300 \mathrm{~K}$ in spectral range from 240 to $550 \mathrm{~nm}$, under the emission monitored at the ${ }^{5} \mathrm{D}_{0} \rightarrow{ }^{7} \mathrm{~F}_{2}$ hypersensitive transition of $\mathrm{Eu}^{3+}$ ion. The excitation spectrum displays broad absorption band centered at $396 \mathrm{~nm}$, corresponding to the $S_{0} \rightarrow S_{1}$ transition of the DBM ligand. This result indicates that the luminescence from these $\mathrm{Eu}^{3+}$-nanostructures is a consequence of sensitization of the europium(III) ion excited state by energy transfer from the corresponding ligands, exclusively as a result of the operative antenna effect of the $\beta$-diketonate (TTA and DBM) ligands.

The emission spectrum of IONCs@SiO ${ }_{2}$-TTA-Eu-DBM nanomaterials was recorded in solid state at $300 \mathrm{~K}$ (Fig. 3e) in the range from 500 to $750 \mathrm{~nm}$, under excitation monitored at $\mathrm{S}_{0} \rightarrow \mathrm{S}_{1}$ transition of $\beta$-diketonate ligand which is centered at $396 \mathrm{~nm}$. The spectrum exhibits narrow emission lines assigned to the ${ }^{5} \mathrm{D}_{0} \rightarrow{ }^{7} \mathrm{~F}_{J}$ transitions (where $J=0-4$ ) of $\mathrm{Eu}^{3+}$ ion, with the ${ }^{5} \mathrm{D}_{0} \rightarrow{ }^{7} \mathrm{~F}_{2}$ hypersensitive one, that is centered at $612 \mathrm{~nm}$ for IONCs@SiO ${ }_{2}^{-}$ TTA-Eu-DBM nanomaterials. It is worth mentioning that the emission spectrum exhibits no broad emission band from the triplet state $\left(\mathrm{T}_{1}\right)$ of the ligands, indicating an efficient ligand-tometal intramolecular energy transfer. ${ }^{72,73}$ In addition, the high
Table 1 Particle size and zeta potential values of the bare samples determined by dynamic light scattering analysis

\begin{tabular}{|c|c|c|}
\hline \multirow[b]{2}{*}{ Nanostructures } & \multicolumn{2}{|c|}{ Zeta potential $(\xi)$} \\
\hline & Value & $\operatorname{STD}^{a}$ \\
\hline${\mathrm{IONCs} @ \mathrm{SiO}_{2}}$ & -39.1 & 0.8 \\
\hline IONCs@SiO ${ }_{2}-\mathrm{TTA}-\mathrm{Eu}$ & 36.0 & 0.4 \\
\hline IONCs@SiO ${ }_{2}-\mathrm{TTA}-\mathrm{Eu}-\mathrm{DBM}$ & -19.8 & 0.1 \\
\hline
\end{tabular}

emission intensity of the ${ }^{5} \mathrm{D}_{0} \rightarrow{ }^{7} \mathrm{~F}_{2}$ transition indicates that the $\mathrm{Eu}^{3+}$ ion is found in chemical environment without the center of inversion, considering that Laporte's rule is slightly relaxed for 4f-4f transitions due to the mixing of opposite parity electronic configurations, ${ }^{60}$ produced by the odd components of a noncentrosymmetric ligand field.

The chemical characteristics of the IONCs surface are significantly affected by the several modifications on the surface functionalization. The main modification is related to the particles superficial charges that were elucidated by the zeta potential measurements. The results showed that the surface charges of IONCs@SiO ${ }_{2}$, IONCs@SiO ${ }_{2}$-TTA-Eu and IONCs@$\mathrm{SiO}_{2}$-TTA-Eu-DBM were $-39.1 \pm 0.8 \mathrm{mV},+36.0 \pm 0.4 \mathrm{mV}$ and $-19.1 \pm 0.1 \mathrm{mV}$, respectively (see Table 1), indicating the presence of charged species in all nanostructures. In the first step of functionalization the IONCs were covered with a layer of $\mathrm{SiO}_{2}$, with negative surface charge. This negative value is related to the chemical characteristics of silica surfaces that 
are mainly dominated by the silanol groups properties, which gives these materials huge hydrophilicity due to the hydrogen bonding interactions, and great affinity to several other molecules and ions owing to the possible dipole and electrostatic interactions. $^{60}$

The different superficial charges of the materials may cause variations in nano-bio interaction between nanomaterials and the protein rich biological fluids, and may change the interaction with red blood cells (RBCs). ${ }^{74}$ Changes on the interaction of these materials with hydrophobic drugs and on the drugs release mechanisms are also expected. ${ }^{75}$ Thus, the need to study the surface engineering of materials by modification with different materials, opens new possibilities in the creation of hybrid materials, where one can combine different properties or even synergistic characteristics can emerge.

The different constituents of the blood plasma and the nano-bio interaction between these constituents of the plasma and the surface of the hybrid NPs can result in different toxicological effects on the RBCs. Interactions originating from stereochemical effects, such as hydrogen bonds and van der Waals forces, can lead to secondary metabolic effects induced by the presence of NPs, which are being neglected by the approaches reported so far in the literature. ${ }^{48,76,77}$

Recently, it has been reported a dynamic interaction phenomenon that occurs in biological environments in which biomolecules can undergo adsorption and desorption processes on the surface of nanomaterials. ${ }^{78,79}$ Such phenomenon results in the formation of a layer of proteins on the surface of nanomaterials known as the protein corona, ${ }^{80}$ this coating influences practically all the biological effects manifested in living organisms. ${ }^{55}$

Here, we analyzed the influence of the functionalization of hybrid nanomaterials with positive and negative charge, as well as the impact of the protein corona formation (hard corona) on the hemolysis of erythrocytes. The hemolysis was evaluated for six different concentrations of each synthesized nanomaterial.

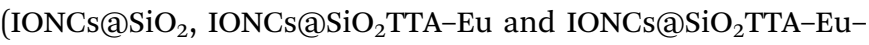
DBM): 15, 30, 75, 150, 225 and $300 \mu \mathrm{g} \mathrm{mL}{ }^{-1}$, respectively. Positive and negative controls were performed in deionized water and, $\mathrm{NaCl} 0.15 \mathrm{~mol} \mathrm{~L}^{-1}$, respectively. When the tests were carried out with IONCs@SiO ${ }_{2}$ dispersion, as well as demonstrated in other studies as silica-based nanomaterials, ${ }^{60,78,81}$ the toxicity was dose-dependent up to the concentration of $300 \mu \mathrm{g} \mathrm{mL} \mathrm{m}^{-1}$ (Fig. 4b, black line). The functionalization of IONCs@SiO ${ }_{2}$ with the TTA-Eu group (resulting in the IONCs@ $\mathrm{SiO}_{2}$ TTA-Eu nanocomposite) lead to a substantial decrease in its cytotoxicity for RBCs, with no hemolysis been observed (Fig. 4b, red line). However, in the presence of DBM it was observed a similar toxicity of IONCs@SiO ${ }_{2}$, leading to the breakdown of about $80 \%$ of the RBCs (Fig. $4 \mathrm{~b}$, blue line). In order to investigate the effect of the DBM on RBCs hemolysis, a test with the isolated DBM ligand was carried out in the same range of concentration $\left(15,30,75,150,225\right.$ and $\left.300 \mu \mathrm{g} \mathrm{mL}{ }^{-1}\right)$. Fig. $4 \mathrm{c}$ and $\mathrm{d}$ show that the DBM presented a higher hemolytic effect on RBCs, justifying the results obtained for the IONCs@ $\mathrm{SiO}_{2}$ TTA-Eu-DBM nanocomposite.
Considering that hemolysis is a biological effect induced by the surface of hybrid NPs, this effect may be related mainly to the amount of atoms exposed to cells at the solid-liquid interface, responsible for chemical interactions. ${ }^{79,82}$ In general, the hemolysis of human RBCs induced by silica NPs (without blood plasma) may be associated with reactive oxygen species (ROS) on the particle surface and electrostatic interactions of deprotonated silanol groups with the membranes of proteins and tetra-alkyl ammonium groups that are present in the membranes. ${ }^{83-85}$ Some works showed that negative surface charges presented in the zeta potential are among the main effects on the hemolysis. Martinez et al. showed that the difference between the surface area values of the studied NPs could interfere with hemolytic assays. ${ }^{60,81,82}$ Therefore, hemolysis assays in a phosphate buffer solution (without plasma) were performed by normalizing the amount of NPs used in the experiments by the largest specific surface area of the NPs they studied. ${ }^{78}$ The researchers then observed that the hemolytic effect presented in their experiments was due to the negative surface charge.

These results agree with the data obtained in this work, where the biggest hemolytic effect was observed for the IONCs@SiO ${ }_{2}$ nanoparticle which presented the most negative zeta potential. However, only the negative zeta potential should not be considered responsible for the cytotoxicity of hybrid NPs. Other mechanisms and interactions such as ROS, hydrogen bonds and van der Waals forces must be deemed responsible for the cytotoxicity observed in this work, since the assay using IONCs@SiO ${ }_{2}$ TTA-Eu-DBM nanocomposite showed a cytotoxicity similar to that of IONCs@SiO ${ }_{2}$. Part of this effect is due to the molecular structure of the DBM ligand that can induce such an effect (hemolysis) as it can promote all possible interactions with the red cell membrane. To check this, hemolytic assay in $\mathrm{NaCl} 0.15 \mathrm{~mol} \mathrm{~L}^{-1}$ solution in the presence of only the DBM ligand was performed (Fig. 4c and d), indicating a strong hemolytic effect on the RBCs. On the other hand, the absence of hemolytic effect induced by the IONCs@SiO ${ }_{2}$ TTAEu may be mainly associated with its positive surface charge, in which the charges on the membrane surface of RBCs are similar, where positively charged tetra-alkyl ammonium groups pass not to interact with the surface of the nanomaterial due to electrostatic repulsion. ${ }^{78,86}$

Besides the nano-bio interaction between hybrid NPs and erythrocytes, several chemical interactions can occur between these same materials and plasma proteins, such as hydrogen bonding, electrostatic interactions and van der Waals forces (hydrophobic interaction, $\pi-\pi$ interaction). ${ }^{87-89}$ Nevertheless, depending on the surface characteristics of the particles, some mechanisms may prevail over others, which may result in the preferential adsorption of different types of proteins from human plasma (Fig. 5a). Selectively, proteins with a molecular weight (MW) from 10 to $25 \mathrm{kDa}$ and from 46 to $135 \mathrm{kDa}$ interact more with IONCs@SiO $\mathrm{S}_{2}$ and IONCs@SiO 2 TTA-Eu-DBM, respectively. On the other hand, for IONCs@SiO ${ }_{2}$ TTA-Eu nanocomposite, it was observed a selective adsorption of proteins with MW around 46 to $80 \mathrm{kDa}$ and high MW proteins, between 

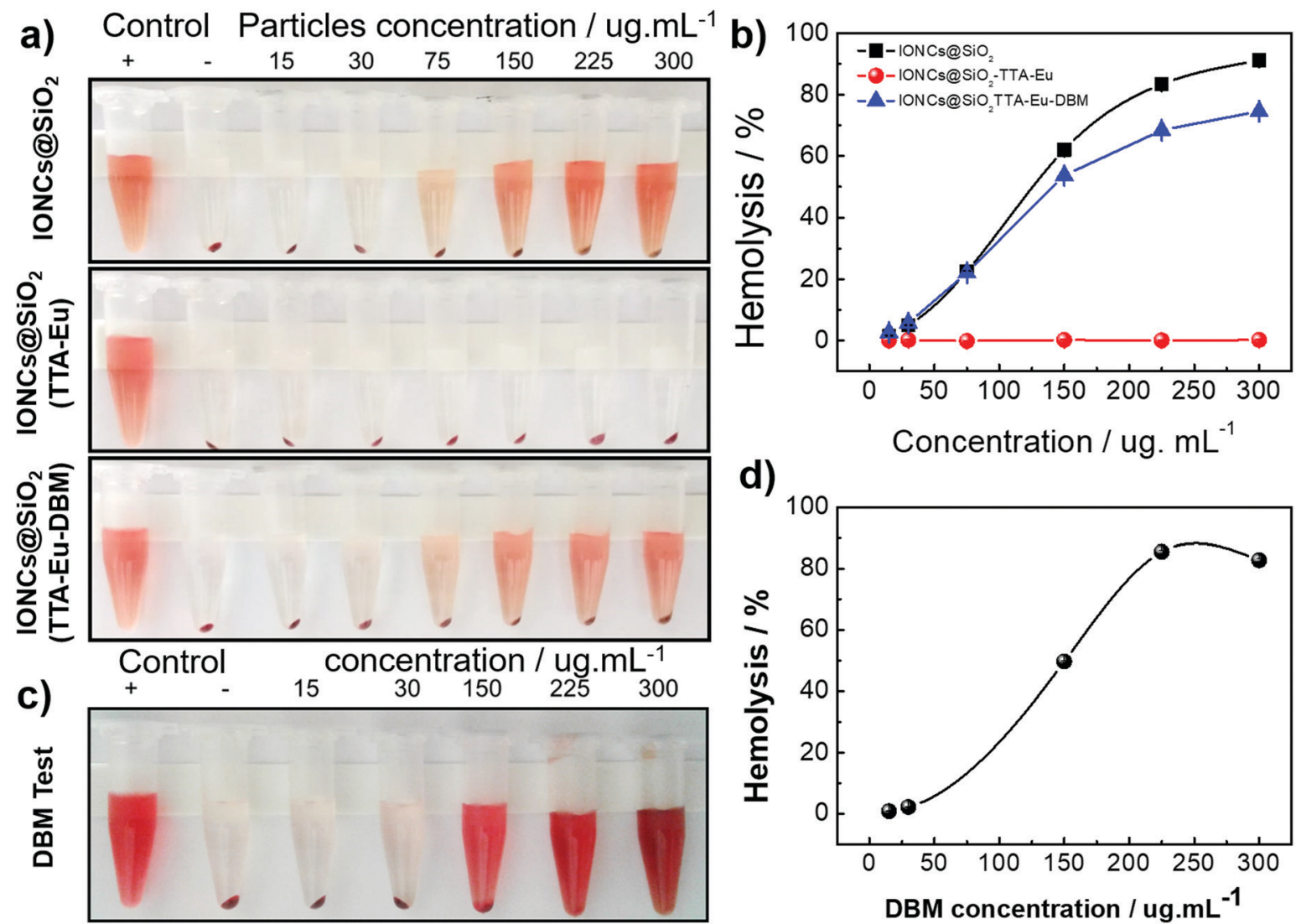

d)

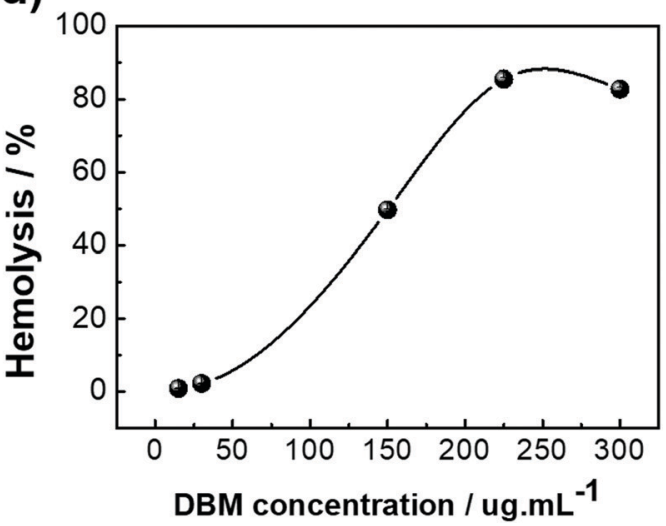

Fig. 4 Evaluation of hemolysis of red blood cells induced by hybrid nanomaterials with different surface chemistry nano-environment: IONCs@SiO 2 , IONCs@SiO 2 TTA-Eu and IONCs@SiO ${ }_{2} T T A-E u-D B M$. (a) A photograph of the results; the red color in the Eppendorf tubes supernatants indicates the disruption of RBCs (release of hemoglobin). Numbers on the top of photograph stand for the concentration of particles, and positive and negative controls were done with deionized water $\left(\mathrm{C}+\right.$ ) and $\mathrm{NaCl} 0.15 \mathrm{~mol} \mathrm{~L} \mathrm{~L}^{-1}$ solution $(\mathrm{C}-$ ), respectively. ( $\mathrm{b}$ and $\mathrm{d})$ Curves for percentage of hemolysis of red blood cells for nanomaterials and DBM ligand, respectively, (c) photograph of the results of hemolysis for DBM ligand.

135-245 kDa. In addition, proteins can be considered amphiphilic, being partially hydrophobic (hydrocarbon radical) and partially hydrophilic (peptide, amino and carboxyl functional groups), ${ }^{74,90,91}$ so that they can interact with hydrophobic and hydrophilic particles. This would explain not just the fact that they were found on the surface of the IONCs@SiO ${ }_{2}$, IONCs@$\mathrm{SiO}_{2}$ TTA-Eu and IONCs@SiO ${ }_{2}$ TTA-Eu-DBM, but also the differences verified (see Fig. 5).

IONCs@SiO 2 particles have hydrophilic silane groups on their surface, allowing them to interact with proteins with stronger forces (i.e. hydrogen bonds, electrostatic interactions and van der Waals forces) than those involved in interactions with hydrophobic surfaces. ${ }^{82}$ This is probably the reason why a slightly larger amount of protein was adsorbed on the particles of IONCs@SiO ${ }_{2}$. Even after three washing steps there was a greater accumulation of proteins on the surface when compared with the sample IONCs@SiO 2 TTA-Eu-DBM.

For the IONCs@SiO ${ }_{2}$ TTA-Eu, a substantially different pattern of proteins was adsorbed on its surface, related to the positive surface charge and the chemical nature of the surface of this hybrid material. van der Waals' forces are highly dependent on surface chemistry and topology, which strongly affects the interface in nano-bio interactions. As a result one
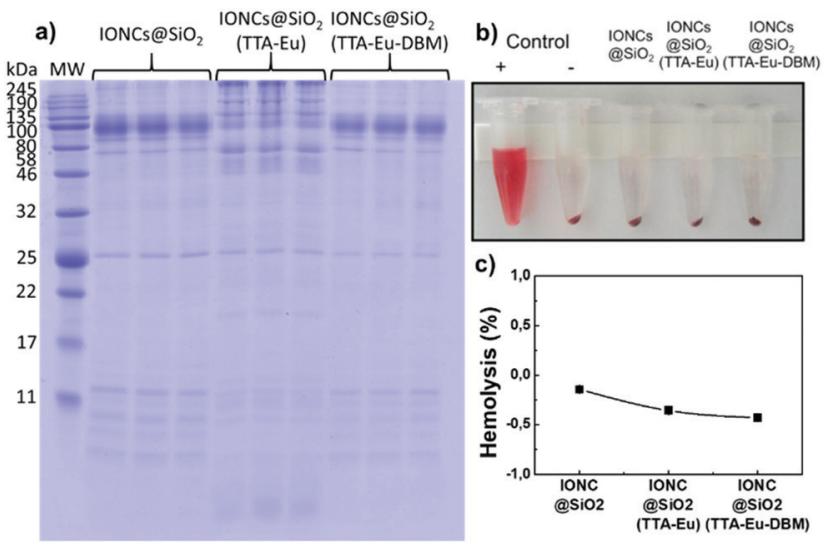

Fig. 5 (a) SDS-PAGE gel of hard corona plasma proteins extracted from hybrid nanomaterials surface $\left(\mathrm{IONCs} \mathrm{CSiO}_{2}, 1 \mathrm{ONCs} \mathrm{SSiO}_{2} \mathrm{TTA}-\mathrm{Eu}\right.$ and IONCs@SiO${ }_{2} \mathrm{TTA}-$ Eu-DBM), after $1 \mathrm{~h}$ incubation in 55\% plasma in PBS solution, at $37{ }^{\circ} \mathrm{C}$ and $100 \mu \mathrm{g} \mathrm{mL}^{-1}$ concentration. (b and c) Image (photograph) and curves, respectively, of the hemolysis assay performed with protein corona coated nanocomposites; the absence of a red color in the Eppendorf tubes supernatants indicates the suppression of RBCs hemolysis by the presence of the protein corona.

observes a selective absorption of proteins found in the SDSPAGE experiments for the hard corona. ${ }^{92}$ It is known that a 
surface containing silanol groups, such as the IONCs@SiO ${ }_{2}$ nanoparticle, will interact with the huge variety of proteins present in any biological fluid, and it is evident here that the presence of different domains containing ligands and ions $\left(\mathrm{Eu}^{3+}\right)$ on the surface of the particles strongly influence the complex protein-nanoparticle interactions.

Regardless of the positive or negative surface charges, the adsorption of plasma biomolecules (mainly proteins) occurred on the surfaces of the NPs for all samples analyzed. Thus, the suppression of hemolysis after the interaction with proteins in all nanocomposites demonstrates that the biomolecule coating acts as a very efficient surface shield, isolating the nanoparticle surface micro-chemical environment, regardless of surface load, as well as other characteristics peculiar to the surface portions used. Similar results were also reported using nanomaterials with similar chemical components. ${ }^{29,82,93}$ Such results reinforce the importance of a careful synthesis of hybrid nanomaterials for nanobiotechnology applications; and the hemolytic assay can be considered as effective tool to probe the influence of surface chemistry on RBCs toxicity towards safe-by-design approaches during hybrid nanomaterials development.

\section{Conclusions}

The synthesis and physico-chemical characterization of magnetic-luminescent nanostructures with high control of morphology and size was performed. The results show that the coating on the IONCs surface with $\mathrm{SiO}_{2}$ was homogeneous, but that some particles showed multinuclei. The silica coating allowed the IONCs to be manipulated in an aqueous medium and thus functionalize the surface with rare earth element $\left(\mathrm{Eu}^{3+}\right)$. Functionalization showed that each domain is homogeneously occupied within the hybrid material, with the magnetic core in the center and the luminescent domain on the surface of the hybrid nanomaterial with a core@shell type structure. After each modification of the hybrid nanomaterial, the surface chemistry of the particles changed drastically, which made it possible to interact in different ways with red blood cells, as well as with plasma proteins. The results suggest that the IONCs@SiO ${ }_{2}$ TTA-Eu have good biocompatibility, presenting non-toxic effects against red blood cells (hemolysis) when compared with IONCs@SiO 2 and IONCs@SiO 2 TTA-Eu$\mathrm{DBM}$, indicating that the ligand DBM may be directly related to the toxic effect. In addition, a hemolysis suppression effect was demonstrated after the interaction of these particles with human plasma proteins, regardless the surface chemistry of the hybrid materials, owing to the formation of a protein corona. Functionalization showed that there is selectivity of the protein molecules that interact with the surface of the materials. Future studies should be carried out exploring these hybrid materials to elucidate the role of the surface's distinct characteristics on cell internalization, biodistribution and toxicological profile.

\section{Conflicts of interest}

There are no conflicts to declare.

\section{Acknowledgements}

The authors thank the financial support by Coordenação de Aperfeiçoamento de Pessoal de Nível Superior (CAPES, Brazil), Conselho Nacional de Desenvolvimento Científico e Tecnológico (CNPq, Brazil), and Sistema Nacional de Laboratórios em Nanotecnologias (SisNANO). Fundação de Amparo à Pesquisa do Estado de São Paulo (FAPESP, Brazil). The authors also extend gratitude to CNPEM open-facilities (TEM, XPS, and Nanotox). We would like to thank Alexandro dos Santos Evangelista da Cruz (LMBT/IFGW/UNICAMP) for support during magnetic measurements.

\section{Notes and references}

1 M. Xuan, J. Shao, J. Zhao, Q. Li, L. Dai and J. Li, Angew. Chem., Int. Ed., 2018, 57, 6049-6053.

2 O. Chen, L. Riedemann, F. Etoc, H. Herrmann, M. Coppey, M. Barch, C. T. Farrar, J. Zhao, O. T. Bruns, H. Wei, P. Guo, J. Cui, R. Jensen, Y. Chen, D. K. Harris, J. M. Cordero, Z. Wang, A. Jasanoff, D. Fukumura, R. Reimer, M. Dahan, R. K. Jain and M. G. Bawendi, Nat. Commun., 2014, 5, 5093.

3 R. Kas, E. Sevinc, U. Topal and H. Y. Acar, J. Phys. Chem. C, 2010, 114, 7758-7766.

4 F. Erogbogbo, K.-T. Yong, R. Hu, W.-C. Law, H. Ding, C.-W. Chang, P. N. Prasad and M. T. Swihart, ACS Nano, 2010, 4, 5131-5138.

5 C. de and M. Donegá, Chem. Soc. Rev., 2011, 40, 1512-1546.

6 R. Costi, A. E. Saunders and U. Banin, Angew. Chem., Int. Ed., 2010, 49, 4878-4897.

7 P. D. Cozzoli, C. Nobile, R. Scarfiello, A. Fiore and L. Carbone, Magnetic Nanomaterials - Fundamentals, Synthesis and Applications, Wiley-VCH Verlag GmbH \& Co. KGaA, Weinheim, Germany, 2017, pp. 217-290.

8 L. Carbone and P. D. Cozzoli, Nano Today, 2010, 5, 449-493.

9 N. Lee, Y. Choi, Y. Lee, M. Park, W. K. Moon, S. H. Choi and T. Hyeon, Nano Lett., 2012, 12, 3127-3131.

10 F. Lin, H.-H. Peng, Y.-H. Yang and R. Doong, J. Nanopart. Res., 2013, 15, 2139.

11 C. Barrera, A. Herrera, Y. Zayas and C. Rinaldi, J. Magn. Magn. Mater., 2009, 321, 1397-1399.

12 J. Kim, J. E. Lee, J. Lee, J. H. Yu, B. C. Kim, K. An, Y. Hwang, C.-H. Shin, J.-G. Park, J. Kim and T. Hyeon, J. Am. Chem. Soc., 2006, 128, 688-689.

13 C. Sun, J. S. H. Lee and M. Zhang, Adv. Drug Delivery Rev., 2008, 60, 1252-1265.

14 J. M. Orozco-Henao, D. F. Coral, D. Muraca, O. MoscosoLondoño, P. Mendoza Zélis, M. B. Fernández van Raap, S. K. Sharma, K. R. Pirota and M. Knobel, J. Phys. Chem. C, 2016, 120, 12796-12809. 
15 P. Guardia, S. Nitti, M. E. Materia, G. Pugliese, N. Yaacoub, J.-M. Greneche, C. Lefevre, L. Manna and T. Pellegrino, J. Mater. Chem. B, 2017, 5, 4587-4594.

16 A. Sathya, P. Guardia, R. Brescia, N. Silvestri, G. Pugliese, S. Nitti, L. Manna and T. Pellegrino, Chem. Mater., 2016, 28, 1769-1780.

17 Y. Li, T. Lin, Y. Luo, Q. Liu, W. Xiao, W. Guo, D. Lac, H. Zhang, C. Feng, S. Wachsmann-Hogiu, J. H. Walton, S. R. Cherry, D. J. Rowland, D. Kukis, C. Pan and K. S. Lam, Nat. Commun., 2014, 5, 4712.

18 P. Tancredi, L. S. da Costa, S. Calderon, O. MoscosoLondoño, L. M. Socolovsky, P. J. Ferreira, D. Muraca, D. Zanchet and M. Knobel, Nano Res., 2019, 12, 1781-1788.

19 S. Laurent, D. Forge, M. Port, A. Roch, C. Robic, L. Vander Elst and R. N. Muller, Chem. Rev., 2008, 108, 2064-2110.

20 P. Podsiadlo, S. G. Kwon, B. Koo, B. Lee, V. B. Prakapenka, P. Dera, K. K. Zhuravlev, G. Krylova and E. V. Shevchenko, J. Am. Chem. Soc., 2013, 135, 2435-2438.

21 P. Guardia, A. Riedinger, S. Nitti, G. Pugliese, S. Marras, A. Genovese, M. E. Materia, C. Lefevre, L. Manna and T. Pellegrino, J. Mater. Chem. B, 2014, 2, 4426.

22 F. Lin, W. Chen, Y.-H. Liao, R. Doong and Y. Li, Nano Res., 2011, 4, 1223-1232.

23 D. Ghosh, Y. Lee, S. Thomas, A. G. Kohli, D. S. Yun, A. M. Belcher and K. A. Kelly, Nat. Nanotechnol., 2012, 7, 677-682.

24 D. Ling and T. Hyeon, Small, 2013, 9, 1450-1466.

25 W. Wu, Z. Wu, T. Yu, C. Jiang and W.-S. Kim, Sci. Technol. Adv. Mater., 2015, 16, 023501.

26 A.-H. Lu, E. L. Salabas and F. Schüth, Angew. Chem., Int. Ed., 2007, 46, 1222-1244.

27 E.-K. Lim, T. Kim, S. Paik, S. Haam, Y.-M. Huh and K. Lee, Chem. Rev., 2015, 115, 327-394.

28 L. U. Khan, L. F. M. Zambon, J. L. Santos, R. V. Rodrigues, L. S. Costa, D. Muraca, K. R. Pirota, M. C. F. C. Felinto, O. L. Malta and H. F. Brito, ChemistrySelect, 2018, 3, 1157-1167.

29 L. U. Khan, R. Petry, A. J. Paula, M. Knobel and D. S. T. Martinez, ChemNanoMat, 2018, 4, 1202-1208.

30 S. Gai, P. Yang, C. Li, W. Wang, Y. Dai, N. Niu and J. Lin, Adv. Funct. Mater., 2010, 20, 1166-1172.

31 F. Erogbogbo, K.-T. Yong, R. Hu, W.-C. Law, H. Ding, C.-W. Chang, P. N. Prasad and M. T. Swihart, ACS Nano, 2010, 4, 5131-5138.

32 C. Kaewsaneha, P. Tangboriboonrat, D. Polpanich and A. Elaissari, ACS Appl. Mater. Interfaces, 2015, 7, 23373-23386.

33 Y.-S. Lin, S.-H. Wu, Y. Hung, Y.-H. Chou, C. Chang, M.-L. Lin, C.-P. Tsai and C.-Y. Mou, Chem. Mater., 2006, 18, 5170-5172.

34 L. U. Khan, Z. U. Khan, R. V. Rodrigues, L. S. da Costa, M. Gidlund and H. F. Brito, J. Mater. Sci.: Mater. Electron., 2019, 30, 16856-16863.

35 P. Guardia, S. Nitti, M. E. Materia, G. Pugliese, N. Yaacoub, J.-M. Greneche, C. Lefevre, L. Manna and T. Pellegrino, J. Mater. Chem. B, 2017, 5, 4587-4594.
36 L. Wu, P.-O. O. Jubert, D. Berman, W. Imaino, A. Nelson, H. Zhu, S. Zhang and S. Sun, Nano Lett., 2014, 14, 3395-3399.

37 F. Côa, M. Strauss, Z. Clemente, L. L. Rodrigues Neto, J. R. Lopes, R. S. Alencar, A. G. Souza Filho, O. L. Alves, V. L. S. S. Castro, E. Barbieri and D. S. T. Martinez, Sci. Total Environ., 2017, 607-608, 1479-1486.

38 G. Palui, T. Avellini, N. Zhan, F. Pan, D. Gray, I. Alabugin and H. Mattoussi, J. Am. Chem. Soc., 2012, 134, 16370-16378.

39 H. R. Neves, R. A. Bini, J. H. O. Barbosa, C. E. G. Salmon and L. C. Varanda, Part. Part. Syst. Charact., 2016, 33, 167-176.

40 C. G. S. De Souza, J. Batista Souza Jr., W. Beck and L. C. Varanda, J. Nanomater., 2017, 2017, 2160278.

41 E. V. Carvalho, D. M. de Paula, D. M. Andrade Neto, L. S. Costa, D. F. Dias, V. P. Feitosa and P. B. A. Fechine, J. Mech. Behav. Biomed. Mater., 2020, 101, 103447.

42 C. G. S. de Souza, J. B. Souza, W. Beck and L. C. Varanda, J. Nanomater., 2017, 2017, 1-9.

43 L. Wortmann, S. Ilyas, D. Niznansky, M. Valldor, K. Arroub, N. Berger, K. Rahme, J. Holmes and S. Mathur, ACS Appl. Mater. Interfaces, 2014, 6, 16631-16642.

44 P. C. Rivas Rojas, P. Tancredi, O. Moscoso Londoño, M. Knobel and L. M. Socolovsky, J. Magn. Magn. Mater., 2018, 451, 688-696.

45 L. A. V. de Luna, D. S. T. Martinez and O. L. Alves, Nanotoxicology: Materials, Methodologies, and Assessments, 2014, pp. 347-361.

46 Y. Zhao, X. Sun, G. Zhang, B. G. Trewyn, I. I. Slowing and V. S. Y. Lin, ACS Nano, 2011, 5, 1366-1375.

47 I. I. Slowing, C. W. Wu, J. L. Vivero-Escoto and V. S. Y. Lin, Small, 2009, 5, 57-62.

48 Y.-S. Lin and C. L. Haynes, J. Am. Chem. Soc., 2010, 132, 4834-4842.

49 C. Gunawan, M. Lim, C. P. Marquis and R. Amal, J. Mater. Chem. B, 2014, 2, 2060.

50 J. Simon, L. K. Müller, M. Kokkinopoulou, I. Lieberwirth, S. Morsbach, K. Landfester and V. Mailänder, Nanoscale, 2018, 10, 10731-10739.

51 R. Rampado, S. Crotti, P. Caliceti, S. Pucciarelli and M. Agostini, Front. Bioeng. Biotechnol., 2020, 8, 166.

52 X. Y. Wong, A. Sena-torralba, K. Muthoosamy, A. Merkoçy and R. Álvarez-Diduk, ACS Nano, 2020, 14(3), 2585-2627.

53 A. K. Barui, J. Y. Oh, B. Jana, C. Kim and J. Ryu, Adv. Ther., 2020, 3, 1900124.

54 M. P. Monopoli, D. Walczyk, A. Campbell, G. Elia, I. Lynch, F. Baldelli Bombelli and K. A. Dawson, J. Am. Chem. Soc., 2011, 133, 2525-2534.

55 M. P. Monopoli, C. Åberg, A. Salvati and K. A. Dawson, Nat. Nanotechnol., 2012, 7, 779-786.

56 M. Peracchia, E. Fattal, D. Desmaële, M. Besnard, J. Noël, J. Gomis, M. Appel, J. D'Angelo and P. Couvreur, J. Controlled Release, 1999, 60, 121-128.

57 H. Yang, T. Ogawa, D. Hasegawa and M. Takahashi, J. Appl. Phys., 2008, 103, 07D526.

58 H. L. Ding, Y. X. Zhang, S. Wang, J. M. Xu, S. C. Xu and G. H. Li, Chem. Mater., 2012, 24, 4572-4580. 
59 L. U. Khan, D. Muraca, H. F. Brito, O. Moscoso-Londoño, M. C. F. C. Felinto, K. R. Pirota, E. E. S. Teotonio and O. L. Malta, J. Alloys Compd., 2016, 686, 453-466.

60 D. S. T. Martinez, A. J. Paula, L. C. Fonseca, L. A. V. Luna, C. P. Silveira, N. Durán and O. L. Alves, Eur. J. Inorg. Chem., 2015, 4595-4602.

61 P. Destro, D. A. Cantane, D. M. Meira, G. dos Santos Honório, L. S. da Costa, J. M. C. Bueno and D. Zanchet, Eur. J. Inorg. Chem., 2018, 1-9.

62 L. S. da Costa and D. Zanchet, Catal. Today, 2017, 282, 151-158.

63 E. R. Leite and C. Ribeiro, Crystalization and Growth of Colloidal Nanocrystals, 2012, pp. 7-17.

64 Y. Chen, E. Johnson and X. Peng, J. Am. Chem. Soc., 2007, 129, 10937-10947.

65 S. Physics and R. August, J. Stat. Phys., 1985, 38, 231-252.

66 E. M. Moreno, M. Zayat, M. P. Morales, C. J. Serna, A. Roig and D. Levy, Langmuir, 2002, 18, 4972-4978.

67 G. Marcelo, F. Catalina, I. Bruvera, C. Marquina and G. Goya, Curr. Nanosci., 2014, 10, 676-683.

68 J. Wang, V. Aguilar, L. Li, F. Li, W. Wang and G. Zhao, Nano Res., 2015, 8, 1906-1916.

69 S. Sarveena, D. Muraca, P. M. Zélis, Y. Javed, N. Ahmad, J. M. Vargas, O. Moscoso-Londoño, M. Knobel, M. Singh and S. K. Sharma, RSC Adv., 2016, 6, 70394-70404.

70 K. Binnemans, Chem. Rev., 2009, 109, 4283-4374.

71 J.-C. G. Bünzli, Coord. Chem. Rev., 2015, 293-294, 19-47.

72 K. Binnemans, Coord. Chem. Rev., 2015, 295, 1-45.

73 L. D. Carlos, Y. Messaddeq, H. F. Brito, R. A. Sá Ferreira, V. de Zea Bermudez and S. J. L. Ribeiro, Adv. Mater., 2000, 12, 594-598.

74 D. Kalyane, R. Maheshwari, N. Raval, A. S. Chauhan and R. K. Tekade, Transportation and biointeraction properties in nanomaterials across biological systems, Elsevier Inc., 2018.

75 A. Hervault, A. E. Dunn, M. Lim, C. Boyer, D. Mott, S. Maenosono and N. T. K. Thanh, Nanoscale, 2016, 8, 21-24.

76 T. Yu, A. Malugin and H. Ghandehari, ACS Nano, 2011, 5, 5717-5728.

77 C. Urata, H. Yamada, R. Wakabayashi, Y. Aoyama, S. Hirosawa, S. Arai, S. Takeoka, Y. Yamauchi and K. Kuroda, J. Am. Chem. Soc., 2011, 133, 8102-8105.
78 D. S. T. Martinez, J. P. V. Damasceno, L. S. Franqui, J. Bettini, I. O. Mazali and M. Strauss, Mater. Sci. Eng., C, 2017, 78, 141-150.

79 L. S. Franqui, M. A. De Farias, R. V. Portugal, C. A. R. Costa, R. R. Domingues, A. G. Souza Filho, V. R. Coluci, A. F. P. Leme and D. S. T. Martinez, Mater. Sci. Eng., C, 2019, 100, 363-377.

80 T. Cedervall, I. Lynch, S. Lindman, T. Berggard, E. Thulin, H. Nilsson, K. A. Dawson and S. Linse, Proc. Natl. Acad. Sci. U. S. A., 2007, 104, 2050-2055.

81 A. J. Paula, D. S. T. Martinez, R. T. A. Júnior, A. G. S. Filho and O. L. Alves, J. Braz. Chem. Soc., 2012, 23, 1807-1814.

82 D. S. T. Martinez, J. P. V. Damasceno, L. S. Franqui, J. Bettini, I. O. Mazali and M. Strauss, Mater. Sci. Eng., C, 2017, 78, 141-150.

83 J. Depasse and J. Warlus, J. Colloid Interface Sci., 1976, 56, 618-621.

84 M. Diociaiuti, F. Bordi, L. Gataleta, G. Baldo, P. Crateri and L. Paoletti, Environ. Res., 1999, 80, 197-207.

85 T. Nash, A. C. Allison and J. S. Harington, Nature, 1966, 210, 259-261.

86 C. Pavan, M. Tomatis, M. Ghiazza, V. Rabolli, V. Bolis, D. Lison and B. Fubini, Chem. Res. Toxicol., 2013, 26, 1188-1198.

87 S. Li, J. J. Mulloor, L. Wang, Y. Ji, C. J. Mulloor, M. Micic, J. Orbulescu and R. M. Leblanc, ACS Appl. Mater. Interfaces, 2014, 6, 5704-5712.

88 X.-Q. Wei, L.-Y. Hao, X.-R. Shao, Q. Zhang, X.-Q. Jia, Z.-R. Zhang, Y.-F. Lin and Q. Peng, ACS Appl. Mater. Interfaces, 2015, 7, 13367-13374.

89 Y. Zhang, J. Zhang, X. Huang, X. Zhou, H. Wu and S. Guo, Small, 2012, 8, 154-159.

90 J. Sund, H. Alenius, M. Vippola, K. Savolainen and A. Puustinen, ACS Nano, 2011, 5, 4300-4309.

91 L. Treuel and G. U. Nienhaus, Handbook of Immunological Properties of Engineered Nanomaterials, 2013, pp. 151-172.

92 A. J. Paula, C. P. Silveira, D. S. T. Martinez, A. G. Souza Filho, F. V. Romero, L. C. Fonseca, L. Tasic, O. L. Alves and N. Durán, ACS Appl. Mater. Interfaces, 2014, 6, 3437-3447.

93 M. de Sousa, C. H. Z. Martins, L. S. Franqui, L. C. Fonseca, F. S. Delite, E. M. Lanzoni, D. S. T. Martinez and O. L. Alves, J. Mater. Chem. B, 2018, 6, 2803-2812. 